\title{
Mapping of pathology curriculum as quadriphasic model in an integrated medical school: how to put into practice?
}

This article was published in the following Dove Press journal:

Advances in Medical Education and Practice

\author{
Ihab Shafek Atta ${ }^{1,2}$ \\ Fahd Nasser AIQahtani ${ }^{3}$ \\ 'Department of Pathology, Faculty of \\ Medicine, Al-Azhar University, (Assuit \\ branch), Cairo, Egypt; ${ }^{2}$ Department of \\ Pathology, Faculty of Medicine, Albaha \\ University, Al Baha, Saudi Arabia; \\ ${ }^{3}$ Department of Radiology, Faculty of \\ Medicine, Albaha University, Al Baha, \\ Saudi Arabia
}

Introduction: Integration is the dynamic interconnectedness at multiple levels based on recursive interactions. Pathology teaching strategy in the integrated curriculum has been widely studied, but mapping pathology in the integrated curriculum has not been fully handled.

Aim of this study: The aim of this work is to address the pathology teaching experience at Albaha School of Medicine.

Methods: For attaining the well-situated integration of pathology, the quadriphasic model for teaching/learning pathology in the integrated curriculum is fully formulated and well conducted. This model is formed on the basis of the incorporation of pathology foundations at all academic levels in 4 phases: Phase I: the introductory course of the preparatory phase; Phase II: formation of the 7-week principle of disease module: 2nd basic year; Phase III: integration of anatomic pathology into system-based basic science modules; and Phase IV: application of clinical perspectives on the pathological background in clinical years.

Results: Inferences acquired through program evaluation as well as student assessment indicate that this model will be of practical use in medical schools. Trivial improvements and changes related to the balance between topics applied and time allocated are extensively needed. Despite the positive feedback obtained, minor pathology topics have been missed or only partially delivered. Conclusion: The quadriphasic model is a novel approach to teaching pathology and needs to be more documented and addressed by traditional medical schools that are in the process of shifting toward an integrated system-based learning. Addition of the module that covers the missed topics is highly recommended, and its content must be reformed annually.

Keywords: integration, pathology, teaching/learning, pathology curriculum

\section{Introduction}

Integration has many definitions and explanations. ${ }^{1,2}$ Achike $^{3}$ described integration as holistic advance wherein the basic sciences are being delivered as a compound of the disciplines one by one and with clinical perception from the early academic phase in a horizontally integrated manner. Furthermore, the 4 major clinical sciences are considered in the teaching of clinical phases in the pre-graduation years of the curriculum in a vertically integrated manner. Another form of integration is the spiral form which is defined as a curriculum involving "learning basic and clinical sciences crosswise" where "both theme and time matter". ${ }^{4}$ This concept was originally introduced by Bruner, who proposed that teaching and reading should involve an evolution of concepts over time. ${ }^{5}$

The integrated system-based curriculum at Albaha School of Medicine (ABSM) in Al Baha province, Saudi Arabia, has accepted a wholly integrated curriculum across all
Correspondence: Ihab Shafek Atta Department of Pathology, Faculty of Medicine, Al-Azhar University, Cairo, Assuit Branch, Egypt

Tel +20 I0 01556079

Email Ihab.bassyouny@azhar.edu.eg

Fahd Nasser AIQahtani

Department of Radiology, Faculty of Medicine, Albaha University, Al Baha, Saudi Arabia

Email fnq900@yahoo.com 
phases of its didactic curriculum. The principal characteristic feature of this novel curriculum is the true application of spiral-based integration through all basic and clinical years. This has been achieved through implementation of systembased basic science modules or blocks for basic years and system-based clinical science modules for clinical years.

At the ABSM, the module involves the study of the 10 body systems separately such as respiratory, gastrointestinal system, cardiovascular system, and so on. The body system modules are divided into 2 main parts, one for the basic phase and its counterpart for the clinical phase. In the basic phase, a module, or an alternative name "block", handles all subjects related to this system from the view of the major basic sciences such as anatomy, histology, physiology, pathology, microbiology, and biochemistry in addition to epidemiology and ethical background. On the other hand, in the clinical phase, these modules deal with subjects on the aspects of clinical view including medicine and surgical background. The teaching of clinical sciences and application of clinical practice have been started from the 1st academic year. Additionally, the basic sciences have been addressed in the timetable of clinical years. ${ }^{6,7}$

An example of the already implemented module for the basic phase is the gastrointestinal tract module. This module is mapped to be implemented for level 5, of the 3rd year. The time duration allocated for the module implementation is 5 weeks for a total of 5 credit units. The skeleton of the module consists of 42 lectures, 2 problem-based learning sessions, 2 self-directed learning (SDL) sessions, 8 practical sessions of 2-h duration each, and 2 seminars. The weight of the pathology includes 12 lectures, 4 practical sessions, and 1 SDL. The integration in this phase lies in the harmonization step of the Harden ladder in which the teachers responsible for different courses or different parts of the same course consult each other and communicate about their courses. In some instances, it reaches the step of nesting in which the pathologist introduces a part of clinical medicine to illustrate the application of pathological principles, and where students develop problem-solving skills. Both harmonization and nesting occupy the 3rd and 4th steps of the Harden ladder. ${ }^{1}$

In the clinical years, the same body system is mapped as the 9th level in the 5th year under the gastroenterology/ hepatology module. The time duration allocated for the module implementation is 5 weeks for a total of 5 credit units. The skeleton of the module consists of 31 lectures, 2 problem-solving learning sessions, 2 SDL sessions, 6 hospital-based teaching sessions of 4-h duration each, and 2 seminars. The weight of the pathology includes 3 lectures and 3 interdisciplinary sessions. These interdisciplinary sessions are done through histology, pathology, medicine, radiology, and surgery. The themes are selected and discussed with the students in the pathology laboratory by experts representing these departments. The role of the pathologist is to help the students recall the pathogenesis of the diseases and illustrate the morphological view, either gross or microscopic, and give a brief description about the outcome and prognosis.

This form of integration is an advanced step and lies in the 9th and 10th step of the Harden ladder. In this situation, the themes are handled by more than one department through one or more settings in the form of multidisciplinary and interdisciplinary integration. ${ }^{1}$ The themes applied are selected by the departments, and all teaching tools, including histological and pathological slides, different radiographs, maps, and others, are prepared. Examples of themes applied to this module are the inflammatory lesions of GIT, GIT neoplasm, and hepatitis. In the inflammatory lesions of GIT, the pathologist discusses with the students the common inflammatory lesions and selects the top 5 to concentrate. In GIT neoplasm, the pathologist collects the area of similarity among different types and illustrates them morphologically. In hepatitis, the differential diagnosis of hepatitis is mapped and started with the most common types. Later, internal medicine and other specialties staff illustrate the clinical and laboratory view.

As pathology is considered a core of medicine and fundamental for all medical students and allied health professionals, ${ }^{8}$ many questions touch the mind: In which phase and level would pathology be mapped in the curriculum? Is it better for students to study pathology early in the preparatory phase or postpone to later on in the basic phase? After deep and critical thinking, the response was to address pathology over all the phases and levels throughout the length of the curriculum.

In the present work, the experience developed from the pathology teaching across the whole period of the curriculum of ABSM has been discussed and addressed, with stress on the distribution of pathology subjects along with all the academic phases. In addition, formulation and adjustment of the teaching strategy and tools as well as the availability of resources for each topic are also addressed.

\section{Methods}

Generally, the ABSM curriculum consists of 3 academic phases (preparatory, basic, and clinical) and 12 levels. The preparatory phase occupies the 1st and 2nd levels; the basic or preclinical phase starts at level 3 and ends at level 6; the clinical phase is mapped from levels 7 to 12 . The basic and clinical sciences are formulated in 10 body system modules allocated in the basic and clinical phases. The ABSM 
pathology curriculum has been disseminated over all the 3 phases of the curriculum.

A pathology course committee was shaped and formulated. The committee consisted of staff members from different departments, mainly from the pathology and radiology departments with sharing from other departments as histology, anatomy, microbiology and biochemistry. The pathology committee also incorporated members from clinical sciences with diverse subspecialties. The aim of the committee was to construct an agreement on the content and teaching strategy for integrating pathology into the curriculum of ABSM. The major role of radiology member is to share, construct and apply the basic and molecular outlines for radio-pathologic integration as an initial step in the foundation of interdisciplinary form of whole curriculum integration which accounted as high level of integration. ${ }^{1}$

The pathology committee reviewed the 6-step model of curriculum development implemented by Kern et al ${ }^{9,10}$ and captured it as a guidance for establishing the pathology curriculum as a rectangular model. These steps are the identification of the problem, assessment of teaching/learning needs, formulation of goals and learning objectives, identification of teaching strategy and tools, implementation, and lastly the evaluation phase.

\section{Results and discussion}

The process of implementing teaching of pathology in the undergraduate curriculum of ABSM has followed the guidelines of the 6-step model for curriculum development applied by Kern et al., ${ }^{9,10}$

\section{Step I: problem identification}

Though there are many studies involved in pathology teaching, all have focused mainly on the strategy of teaching/ learning, ${ }^{11-14}$ and to a little extent, on matching the learning style with pathology teaching. ${ }^{14,15}$ Few studies have been carried out to map a scaffold for teaching pathology to undergraduates. Some Universities concentrate more on teaching general pathology rather than anatomic pathology, while others implement teaching pathology as a whole block in the basic phase and concentrate mainly on major common themes and ignore others. Others select the topics to be taught in the basic phase and transfer some topics to the clinical phase. These topics are, in fact, ignored partially or completely later on. Hence, no unified pathology curriculum was established. Many curricula have been studied and reviewed by the pathology committee, and there is much of evidence for the deficiency in the teaching foundations of pathology as gross and microscopic specimens, uncovered topics, time applied for pathology teaching, and assessment strategies that are knowledge-based rather than skill-based.

\section{Step 2: assessment of teaching/learning needs}

Investigating the topics covered in many pathology textbooks and observations of students through focus groups and revision of pathology curriculum of some international and global schools have resulted in the identification of pathology topics that must be covered at all academic levels (Table 1).

\section{Step 3: formulation of goals and learning objectives}

The critical goal is to provide ABSM students with the basic and essential competencies required for understanding the etiology/pathogenesis of diseases, identification of the morphology of pathological specimens, histopathological examination, and reporting and carrying out differential diagnosis and recommendations needed.

Learning objectives criteria were prepared by the pathology committee based on the selection of pathology area that must be addressed for each phase and level (Table 1). These objectives were prepared according to the SMART criteria and classified according to learning domains of Bloom et al. ${ }^{16,17}$ Selection of the content was based on the recognized objectives. Regarding general pathology, all topics (and their content of general pathology) are put in a discrete module "principle of disease" and mapped in the 1st semester of the 2nd academic year.

Other objectives related to anatomic pathology and its related content are disseminated all over the corresponding modules in all academic years of the undergraduate curriculum. Also, learning objectives with clinical applications related to all body systems are organized and allocated in the corresponding modules in the clinical phase.

\section{Step 4: teaching/learning strategy and selection of the teaching tool}

After formulating the objectives, pathology was distributed among 4 phases, the preparatory phase, general pathology in the basic phase, systemic pathology in basic phase, and finally pathology topics with clinical application in the clinical phase. Teaching strategy has been divided into contents and educational means. ${ }^{9}$ To improve pathology teaching, diverse instructional methods and tools were recognized and operated. These instructional tools are appropriate to pathology teaching at all levels (Table 1). The 4 phases of pathology teaching are summarized as follows: 
Table I Mapping of themes, instructional methods, and assessment tools relevant to the pathology curriculum through the academic phases

\begin{tabular}{|c|c|c|c|c|c|}
\hline Phase & & Theme applied & How to study & Instruction tools & Mode of assessment \\
\hline $\begin{array}{l}\text { Preparatory } \\
\text { phase }\end{array}$ & $\begin{array}{l}\text { I: introductory } \\
\text { course of the } \\
\text { preparatory phase }\end{array}$ & $\begin{array}{l}\text { Introductory pathology } \\
\text { course including definitions, } \\
\text { broad classification, } \\
\text { pathogenesis, morphology } \\
\text { (either gross or } \\
\text { microscopic), fate and } \\
\text { complications, and divisions } \\
\text { of anatomic pathology }\end{array}$ & $\begin{array}{l}\text { Integrated within syllabi } \\
\text { of natural sciences } \\
\text { (physics, chemistry, and } \\
\text { biology) }\end{array}$ & $\begin{array}{l}\text { Lectures and practical } \\
\text { laboratory sessions }\end{array}$ & $\begin{array}{l}\text { MCQs, short essays, } \\
\text { and OSPE }\end{array}$ \\
\hline \multirow[t]{2}{*}{$\begin{array}{l}\text { Basic science } \\
\text { phase }\end{array}$} & $\begin{array}{l}\text { II: formation of } \\
\text { 7-week principle of } \\
\text { disease module: } 2 \text { nd } \\
\text { basic year }\end{array}$ & $\begin{array}{l}\text { All themes related to } \\
\text { general pathology }\end{array}$ & $\begin{array}{l}\text { Integrated with } \\
\text { microbiology, } \\
\text { parasitology, ethics, and } \\
\text { community medicine }\end{array}$ & $\begin{array}{l}\text { Lectures, practical } \\
\text { laboratory sessions, } \\
\text { PBL, SDL, seminars, } \\
\text { and field visits }\end{array}$ & $\begin{array}{l}\text { MCQs, EMQs, short } \\
\text { essays, case scenario- } \\
\text { based questions, and } \\
\text { OSPE }\end{array}$ \\
\hline & $\begin{array}{l}\text { III: integration of } \\
\text { anatomic pathology } \\
\text { into system-based } \\
\text { basic science } \\
\text { modules }\end{array}$ & $\begin{array}{l}\text { All themes related to } \\
\text { anatomic pathology }\end{array}$ & $\begin{array}{l}\text { Integrated with } \\
\text { microbiology, } \\
\text { parasitology, ethics, } \\
\text { community, and medicine } \\
\text { related to the } 10 \text { body } \\
\text { systems }\end{array}$ & $\begin{array}{l}\text { Lectures, practical } \\
\text { laboratory sessions, } \\
\text { PBL, SDL, seminars, } \\
\text { and field visits }\end{array}$ & $\begin{array}{l}\text { MCQs, EMQs, short } \\
\text { essays, OSPE, case } \\
\text { scenario-based } \\
\text { questions, and OSCE }\end{array}$ \\
\hline $\begin{array}{l}\text { Clinical } \\
\text { science phase }\end{array}$ & $\begin{array}{l}\text { IV: application of } \\
\text { clinical perspectives } \\
\text { on the pathological } \\
\text { background in } \\
\text { clinical years }\end{array}$ & $\begin{array}{l}\text { Most themes are related } \\
\text { to inflammatory and } \\
\text { neoplastic lesions }\end{array}$ & $\begin{array}{l}\text { Selected themes related } \\
\text { to anatomic pathology } \\
\text { with clinical correlation }\end{array}$ & $\begin{array}{l}\text { Lectures, PBL, SDL, } \\
\text { bedside teaching, } \\
\text { clinical case } \\
\text { orientation, seminars, } \\
\text { and skill laboratory } \\
\text { sessions }\end{array}$ & $\begin{array}{l}\text { MCQs, EMQs, short } \\
\text { essays, case scenario- } \\
\text { based questions, long } \\
\text { case exam, and OSCE }\end{array}$ \\
\hline
\end{tabular}

Abbreviations: MCQs, multiple-choice questions; OSPE, objective structured practical exam; PBL, problem-based learning; SDL, self-directed learning; EMQs, extended matching questions; OSCE, objective structured clinical exam.

Phase I: the introductory course of the preparatory phase

It comprises the 1 st year of the curriculum. In this phase, the introductory pathology course is implemented. The topic is in the form of definitions such as "what does pathogenesis mean?" and gives an idea about the steps for studying diseases and a broad classification of topics.

Phase II: formation of the 7-week principle of disease module: 2 nd basic year

The 2nd phase of pathology teaching in the ABSM curriculum where pathology is mapped is a 7-week module termed principle of disease in which general pathology is heavily addressed. In addition, appropriate topics from microbiology, biochemistry, terminology and ethics are selected and inserted in an integrated form to form the core of the principle of disease module.

The principle of disease module is built into the 1 st semester of the 2 nd academic year. In this module, topics of general pathology are taught in an integrated manner with other basic sciences such as microbiology and pharmacology. The teaching tools are diverse including interactive lectures, SDL, practical sessions, seminars, and problembased learning. In addition, some field visits to hospital laboratories are addressed.

\section{Phase III: integration of anatomic pathology into system-based basic science modules}

In these integrated basic modules, all anatomic pathology topics are addressed and allocated in the corresponding systembased basic science modules in the 2nd and 3rd academic years. These modules are oriented vertically through levels 3 up to 6 . The definition, epidemiology, etiology, pathogenesis, risk factors, morphology (either gross or microscopic), the clinical picture including symptoms and signs, complications, fate and prognosis, diagnostic criteria, clue and tools, and differential diagnosis for all branches of anatomic pathology are heavily addressed in these modules. Teaching is conducted through lectures, and integration of pathology and histology in practical sessions in which the histologist describes the normal structure followed by the pathologist who discusses the pathological findings with the students. Other tools like tutorials and site visits to pathology units in local hospitals are also implemented. 
Phase IV: application of clinical perspectives on the pathological background in clinical years through multidisciplinary and interdisciplinary integration steps

In the 4th, 5th, and 6th clinical years, anatomic pathology is addressed as a major topic related to system-based clinical science modules, for example, GIT tumors from a pathological view in the gastroenterology module and inflammatory lesions of the renal system from a pathological view in the urology module.

In all modules where pathology is addressed, the intended learning outcomes and content are reliable with the different clinical modules throughout the clinical phase. Teaching tools are in the form of case scenarios with discussions from pathological and clinical views, seminars with objectives covering pathological points, and interactive lectures to refresh and update knowledge and problem-solving skills. Other tools used are videos of real cases, role play/simulators, and correlation of pathological findings with clinical pictures through real patients. This phase is implemented through multidisciplinary and interdisciplinary steps of integration in which the themes are handled through multiple disciplines in one session across practical, tutorial, case scenario, or even seminar presentation. ${ }^{18}$

\section{Step 5: implementation phase}

For a good implementation of the module, allocation of financial as well as human resources is important. The main obstacles in implementing the pathology course were in the form of marked shortages in the pathology staff. The fundamental learning facilities, equipment, and teaching tools were painstaking during the phase of current needs assessment. A variety of gross specimens and histopathological slides were deficient.

\section{Step 5: evaluation and feedback}

Through all phases, student assessment is carried out and diverse assessment methods are operated. Competences in pathology are assessed in the form of quizzes and the final exam in the preparatory phase, while for Phase II and Phase III, 1) continuous assessment is conducted in the form of regular quizzes, seminar activity, SDL assessment, and problem-based learning discussion and 2) final assessment is carried out using different grades of multiple-choice questions, extended matching questions, and objective structured practical exam that measures the skills acquired through interpretation of gross specimens and identification of histopathological slides and how to do differential diagnosis and recommendations needed.

In Phase IV, the assessment is in the form of objective structured clinical exam, short case scenario, and logbook assessment.

Inferences from students' performance in pathology in all phases have been implemented. After implementing the pathology module in 5 ranks of students, the failure rates in the principle of disease, in which general pathology was embedded, were $6 \%, 5 \%, 8 \%, 8 \%$, and $7 \%$ ( $\%$ of total students' scores below 60\%) in the years 2013, 2014, 2015, 2016, and 2017, respectively. Most of the students who failed were generally irregular in attendance in different practical learning activities of the module.

Program evaluation was carried out on the last day of each module all through the 6 academic years. Through the years 2013-2017, evaluation of the pathology course was implemented in the preparatory phase, in basic science phase through evaluation of principle of disease module and other pathology core represented in both basic system module and clinical science module. The evaluation was performed using students' and faculty self-administered questionnaires as a part of quality assessment (Table 2).

Table 2 Results of pathology curriculum evaluation obtained via well-constructed student questionnaire

\begin{tabular}{lll}
\hline Phase & Domain assessed & Percentage $^{\text {a }}$ \\
\hline $\begin{array}{l}\text { I: introductory course } \\
\text { of the preparatory }\end{array}$ & $\begin{array}{l}\text { Introductory pathology } \\
\text { course in the preparatory }\end{array}$ & 95 \\
phase & phase & \\
Il: formation of 7-week & Content of principle of the & 75 \\
principle of disease & disease module & \\
module: 2nd basic year & Teaching/learning facilities & 88 \\
& Instruction tools & 85 \\
& Time allocated & 56 \\
& Assessment tool & 88 \\
III: integration of & Themes applied & 90 \\
anatomic pathology & Teaching/learning facilities & 91 \\
into system-based & Instruction tools & 87 \\
basic science modules & Time allocated & 54 \\
& Assessment tool & 76 \\
IV: application of & Correlations of pathology & 87 \\
clinical perspectives & with the clinical findings & \\
on the pathological & Teaching/learning facilities & 90 \\
background in clinical & Instruction tools & 95 \\
years & Time allocated & 65 \\
& Assessment tool & 71 \\
\hline
\end{tabular}

Note: aFigures existing are the mean of percentages attained from the 5 student cohorts in the period between 2013 and 2017. 
Regarding the pathology introductory course allocated for preparatory phase, the student satisfaction was high at $95 \%$, and a minority of students was unsatisfied with some topics and stated that "more time is needed for some topics to be fully addressed and understood".

Regarding the principle of disease module, the students' satisfaction was as follows: with the module content $75 \%$, with the facilities applied $88 \%$, with the instructional methods $85 \%$, and with assessment tools $88 \%$. A minority of students (18\%) commented that there was difficulty in understanding the histopathological examination of some specimens, and hence, such conflicts were evoked, and accurate histopathological diagnosis cannot be reached which was a drawback in their performance. Other students $(10 \%)$ commented more time must be added to the module. The students' satisfaction with the system-based basic science modules was high: theme applied $90 \%$, teaching facilities $91 \%$, instruction tools $87 \%$, time allocated $54 \%$, and assessment tools $77 \%$. Some comments were focused on practical sessions and difficulty of histopathological examination. In the system-based clinical science module, the students' satisfaction regarding theme applied was $87 \%$, teaching facilities $90 \%$, instruction tools $95 \%$, time allocated $65 \%$, and assessment tool $71 \%$. The comments were about the imbalance between time allocated and theme applied.

As a part of the 5-year periodic curricular reform, ${ }^{19}$ the newly developed pathology teaching/learning approach was elicited to map the pathology all over the academic years. The previous one was designed to put the main pathology course for the 2nd and 3rd basic sciences and as a reviewing lecture specified for each system-based module applied for the 4th, 5th, and 6th clinical years. This program was implemented over the first 5 iterations. The newly adopted approach was implemented in the 6 th and 7 th iteration. For comparative study between the new and old program, we selected the last 2 iterations from the old program to be compared with the newly adopted pathology program. For this purpose, the students' achievement in pathology was selected for the first 3 basic years and the last 3 clinical years for both groups representing the old and new programs. Pathology questions and its related students score were identified and selected from each module and categorized as a total for both basic and clinical years. All students' score and statistical analysis are summarized in Table 3 and Figures 1 and 2.

The students' performance showed enhancement in the newly adopted approach compared with the old one (Table 3). No significant $P$ values were obtained between each domain of the new approach with its corresponding domain in old approach. On the other hand, a significant $P$ value was obtained on doing global comparison between all domains in old and new approaches.

Table 3 Comparative study between the old and new teaching/learning pathology approaches

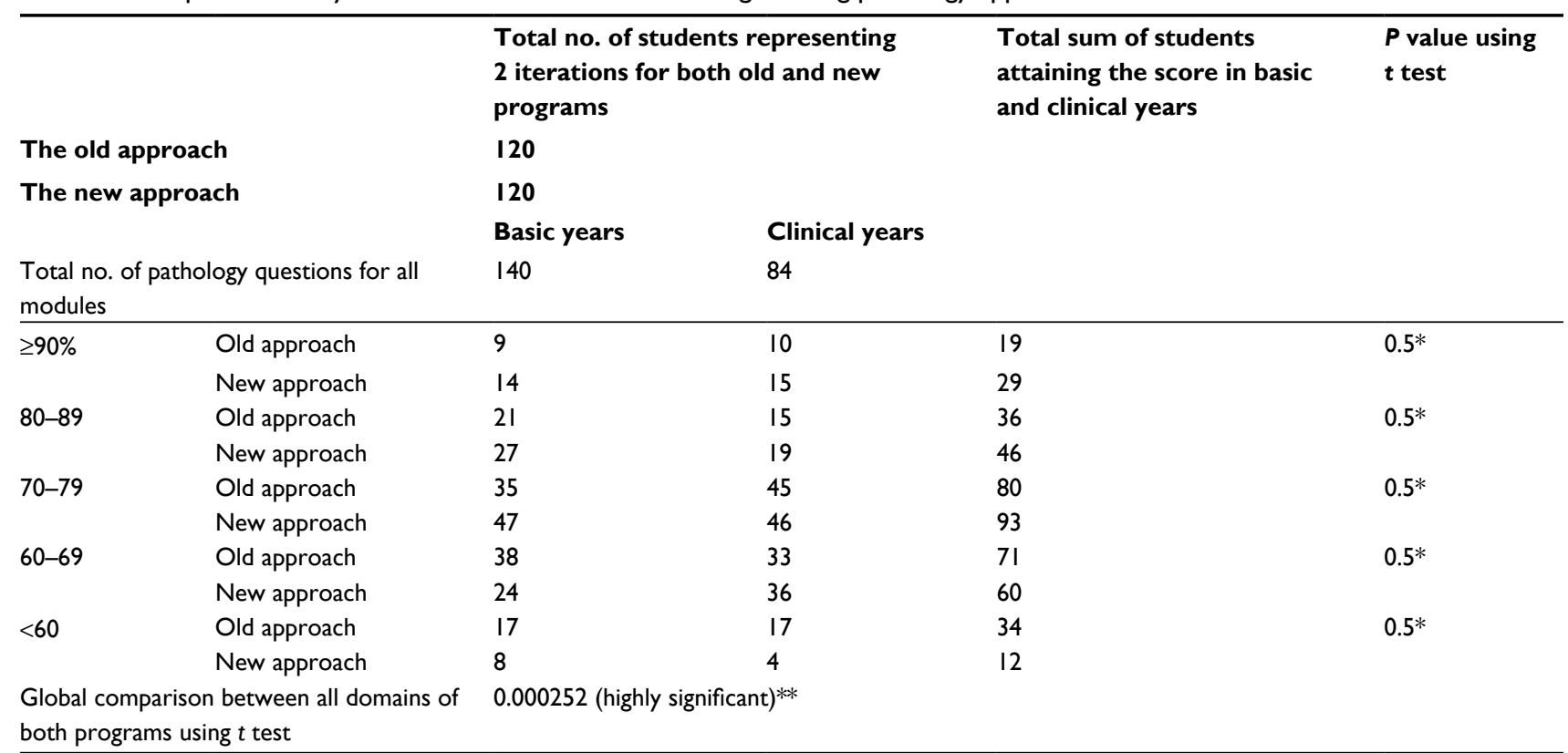

Notes: *No significant $P$ values were obtained between each domain of the new approach with its corresponding domain in old approach. **Significant $P$ value was obtained on doing global comparison between all domains in old and new approaches. 


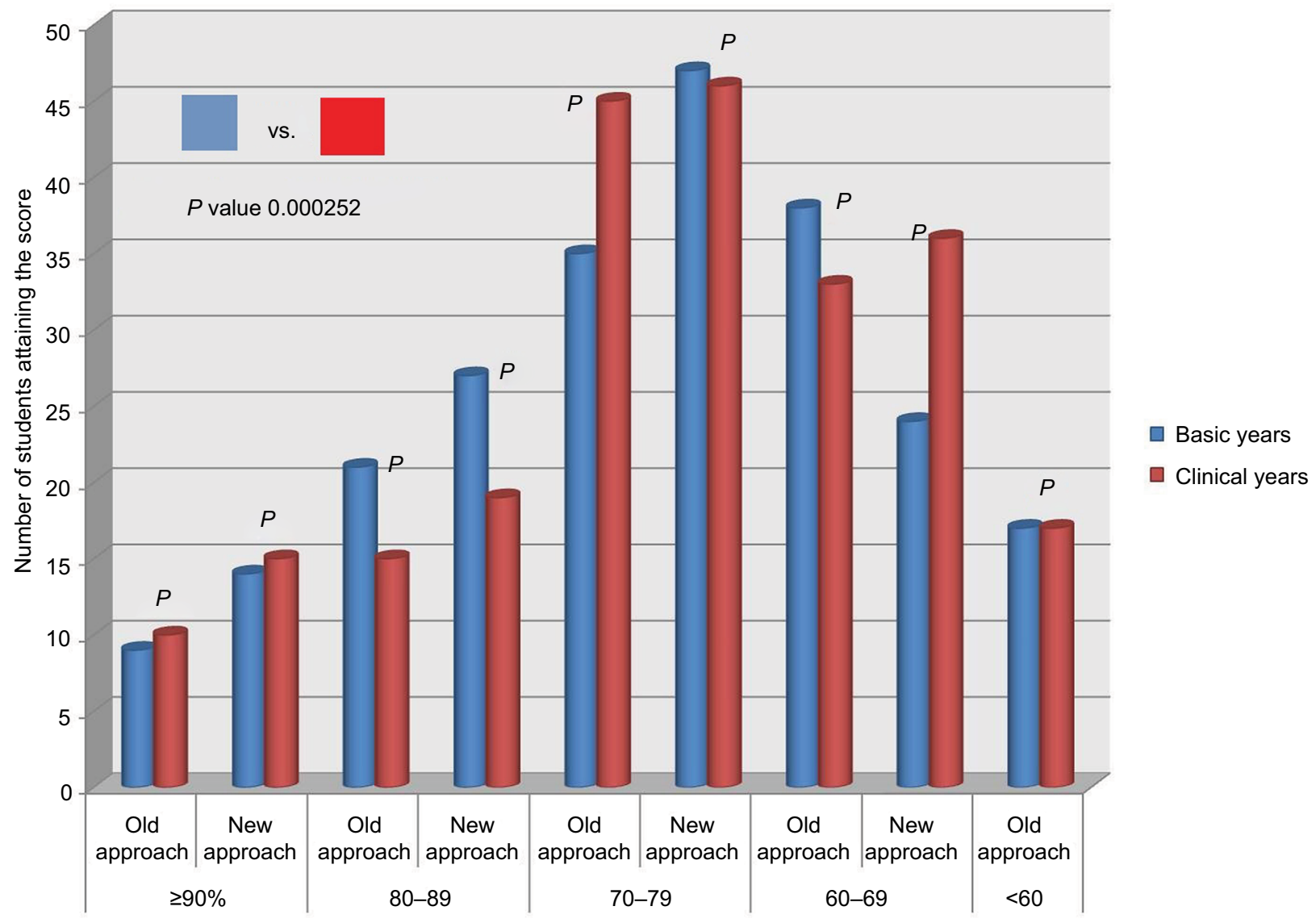

Figure I Illustration of students' scores in both the old and new teaching/learning pathology approaches.

Total number of students for both basic and clinical years

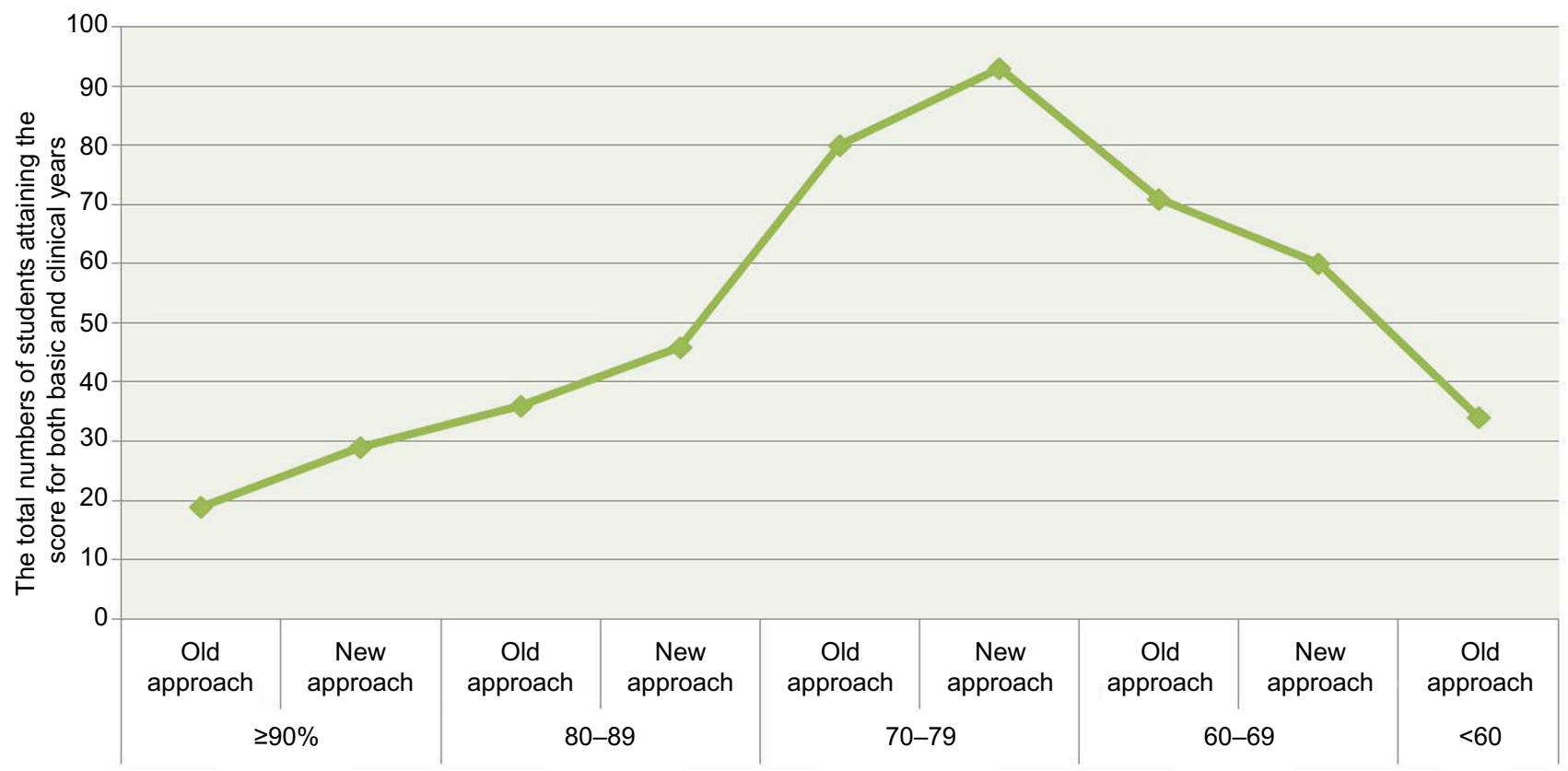

Figure 2 Illustration and summary of the mapping of students' scores for both the old and new teaching/learning pathology approaches. 


\section{Conclusion}

Integrating pathology as a quadriphasic model in the undergraduate curriculum of ABSM is as a novel and exclusive experience that is of valuable study. Pathology teaching was implemented in 4 phases: Phase I: the introductory course of the preparatory phase; Phase II: formation of the 7-week principle of disease module: 2nd basic year; Phase III: integration of anatomic pathology into system-based basic science modules; and Phase IV: application of clinical perspectives on the pathological background in clinical years through multidisciplinary and interdisciplinary integration steps.

The 6-step advance for development of curriculum was employed to conduct this practice and experience.

Inferences resulted from the students' performance and evaluation of the pathology curriculum as a whole were approving of the permanence of this practice. The negative feedback obtained from the students' inference has been kept in mind and prioritized during last program reform. Hence, trivial modification in the form of harmonizing between educational teaching themes or topic and time allocated was applied; also, most of the deficiencies were tolerated and managed. Utilization of pathology web access and communication system to provide morphological information about gross and histopathological examination was done to compensate the partial defect in some areas of anatomic pathology. Despite these changes that have been done, some topics in pathology, either general or anatomic, have been missed in the curriculum, and this may be considered as cons in the integrated learning, and therefore, the addition of the 5th step in pathology teaching is highly advised. This 5 th step must focus on the foundation of the extra module to include the missed or partially taught topics in all medical sciences and is referred to as "pitfall module or module of hidden topics" and mapped in the curriculum of medical schools. This module is not static, and its content must be changed annually to cover the topics missed in the running teaching rank. This rectangular pathology teaching model is appropriate for implementation in traditional medical schools which are paying attention to challenges and paradigm shift toward the integrated learning. One of the medical schools interested in the paradigm shift toward integration in Egypt is Al-Azhar Medical School, and this rectangular pathology teaching model is most suitable for pathology teaching and has to be studied and implemented in the integrated Al-Azhar curriculum.

\section{Disclosure}

The authors report no conflicts of interest in this work.

\section{References}

1. Harden RM, Crosby J, Davis MH, Howie PW, Struthers AD. Task-based learning: the answer to integration and problem-based learning in the clinical years. Med Educ. 2000;34:391-397.

2. Muller JH, Jain S, Loeser H, Irby DM. Lessons learned about integrating a medical school curriculum: perceptions of students, faculty and curriculum leaders. Med Educ. 2008;42:778-785.

3. Achike FI. The temporal and challenging faces of integration in medical education: the fate of pharmacology. Indian J Pharmacol. 2011;43(3):227-231.

4. Bandiera G, Boucher A, Neville A, Kuper A, Hodges B. Integration and timing of basic and clinical sciences education. Med Teach. 2013;35(5):381-387.

5. Bruner JS, editor. The Process of Education. Cambridge, MA: Harvard University Press; 1960.

6. Harden R. The integration ladder: a tool for curriculum planning and evaluation. Med Educ. 2000;34:551-557.

7. Bradley P, Mattick K. Integration of basic and clinical sciences-AMEE 2008. Plymouth: Peninsula College of Medicine and Dentistry; 2008.

8. Fenderson BA. Strategies for teaching pathology to graduate students and allied health professionals. Hum Pathol. 2005;36:146-153.

9. Kern DE, Thomas PA, Howard DM, Bass EB, editors. Curriculum Development for Medical Education: A Six-Step Approach. Baltimore, MA: The Johns Hopkins University Press Center; 1998.

10. Ljuca F, Lozo S, Simunovic V, Bosse H-M, Kadmon M [homepage on the Internet]. Curriculum development. Manual of Teaching and Learning in Medicine. Available from: http://www.bhmed-emanual. org/. Accessed March 17, 2014.

11. Damjanov I. Teaching of pathology at more than one level. Hum Pathol. 2005;36(2):135-138.

12. Fermozelli JA, Cesaretti MLR, Barbo MLP. Blended learning strategies in teaching general pathology at a medical course. J Bras Patol Med Lab. 2017;53:(3):202-209.

13. Maley MAL, Harvey JR, de Boer BW, Scott NW, Arena GE. Addressing current problems in teaching pathology to medical students: blended learning. Med Teach. 2008;30:1.

14. Atta IS, AlQahtani FN. How to adjust the strategy of radiopathologic teaching to achieve the learning outcomes? Int J Med Sci Public Health. 2018;7(2):86-91

15. Atta IS, AlQahtani FN, Alghamdi TA, Mankrawi SA, Alamri AM. Can pathology teaching' strategy be affected by the students' learning style and to what extent the students' performance be affected? Glo Adv Res J Med Sci. 2017;6(11):296-301.

16. Bloom B, Mesia B, Krathwohl D. Taxonomy of Educational Objectives (The Affective Domain \& The Cognitive Domain). New York, NY: David McKay; 1993.

17. Anderson LW, Krathwohl DR, editors. A taxonomy for learning, teaching, and assessing: A revision of Bloom's taxonomy of educational objectives. Allyn and Bacon; 2001.

18. Atta IS, AlQahtani FN. Integrated pathology and radiology learning; an example of an interdisciplinary integrated form. Adv Med Educ Pract. 2018;9:527-533.

19. Atta IS, AlQahtani FN. Matching medical student achievement to learning objectives and outcomes: a paradigm shift for an implemented teaching module. Adv Med Educ Pract. 2018;5:227-233. 
Advances in Medical Education and Practice

Dovepress

\section{Publish your work in this journal}

Advances in Medical Education and Practice is an international, peerreviewed, open access journal that aims to present and publish research on Medical Education covering medical, dental, nursing and allied health care professional education. The journal covers undergraduate education, postgraduate training and continuing medical education including emerging trends and innovative models linking education, research, and health care services. The manuscript management system is completely online and includes a very quick and fair peer-review system. Visit http://www.dovepress.com/testimonials.php to read real quotes from published authors.

Submit your manuscript here: http://www.dovepress.com/advances-in-medical-education-and-practice-journal 